\title{
Orta Toroslarda Karbonatı Kayaçlar ile İlişkili Sarıveliler (Karaman) Floritlerinin Nadir Toprak Element Jeokimyası
}

\author{
Yusuf URAS ${ }^{1 *}$, Cihan YALÇIN ${ }^{2}$, Yaşar İNCEDİş ${ }^{1}$, Muhittin KARAMAN ${ }^{3}$ \\ ${ }^{1}$ Kahramanmaraș Sütçü İmam Üniversitesi, Jeoloji Mühendisliği Bölümü, 46100, Kahramanmaras \\ ${ }^{2}$ Sanayi ve Teknoloji Bakanlığı, Burdur İl Müdürlüğü, 15100, Burdur \\ 3 İstanbul Teknik Üniversitesi, Jeoloji Mühendisliği Bölümü, 34100, İstanbul \\ *1 uras74@gmail.com, ${ }^{2}$ cihan.yalcin@ sanayi.gov.tr
}

\begin{abstract}
Öz: Orta Toroslar'da karbonatlı kayaçlar ile ilişkili Zn-Pb yatakları ile barit ve florit zenginleşmeleri bulunur. Florite ait Nadir Toprak Elementleri (NTE) kökensel yorumlamada kullanılır. Orta Toroslarda yer alması ve bölgeye yakın alanlarda da florit oluşumlarına rastlanılması sebebiyle Sarıveliler floritinin oluşumunun ortaya konulması önem arz eder. Bu çalışmanın amacı floritin oluşumu ve NTE jeokimyasının ortaya konularak diğer yataklar ile karşılaştırılmasıdır. Sarıveliler ilçesi batısında Aladağ Birliğine ait Erken-Orta Triyas yaşlı kireçtaşları florit içerir. Damar tipi şeklinde ve epijenetik oluşumlu cevherleşmede parajenez florit, galenit, kuvars ve kalsitten oluşur. Sarıveliler floritlerinin NTE jeokimyası, floritlerin NTE bakımından fakir olduğunu gösterir. Floritler, kireçtaşları içerisinde gelişmiş kırık ve çatlaklarda hidrotermal evrede oluşmuştur. Düşük Y oranları, cevherleşmede formasyon sularının etkin olduğunun göstergesidir. Cevher oluşumunda ortam düşük sıcaklık ve yüksek oksijen fugasitesine sahiptir. Sarıveliler floritleri $(\mathrm{Tb} / \mathrm{Yb})_{\mathrm{n}}-(\mathrm{La} / \mathrm{Yb})_{\mathrm{n}}$ diyagramında New Mexico kristalize alanında, $(\mathrm{La} / \mathrm{Yb})_{\mathrm{n}}-(\mathrm{Eu} / \mathrm{Eu} *)_{\mathrm{n}}$ ve $\mathrm{Sr}-(\mathrm{Eu} / \mathrm{Eu} *)_{\mathrm{n}}$ diyagramlarında Büyükkızılcık floritlerine benzer alanda, $\mathrm{Sc} / \mathrm{Eu}-\mathrm{Sr}$ diyagramında Akdağmadeni floritleri alanında ve $\mathrm{Sc}-\sum \mathrm{REE}$ diyagramında ise ağır metaller alanında dağılım göstermektedir.
\end{abstract}

Anahtar kelimeler: Florit, Aladă̆ Birliği, Sarıveliler (Karaman), nadir toprak elementi (NTE).

\section{Rare Earth Element Geochemistry Of Sarıveliler (Karaman) Fluorites Related To Carbonate Rocks in Middle Taurus}

\begin{abstract}
Zn}-\mathrm{Pb}$ ore deposits and carbonate associated barite and fluorite enrichments/mineralization are present in the Middle Taurus. Rare Earth Elements (REE) belonging to fluorite are used to interpretation of the origin. It is important to reveal the formation of Sariveliler fluorites due to located in Central Taurus and presence of fluorite in areas close to the region. The aim of this study is to reveal the formation of fluorite and REE geochemistry and to compare with other deposits. To the west of Sarıveliler district, Early-Middle Triassic aged limestones of Aladağ Unit contains fluorite. The paragenesis contains fluorite, galena, quartz and calcite in the vein type and epigenetic formation with mineralization. Geochemical investigation of REE of Sarıveliler Fluorites exhibit that fluorite are poor in REE. Fluorites formed in hydrothermal phase in fractures and cracks developed within limestone. Low Y rates indicate that formation waters are effective in mineralization The environment had low temperature and high oxygen fugacity in ore formation. Sarıveliler fluorites show distribution crystalline are in New Mexico area on $(\mathrm{Tb} / \mathrm{Yb})_{\mathrm{n}}-(\mathrm{La} / \mathrm{Yb})_{\mathrm{n}}$ diagram, in similar area to Büyükkızılcık fluorites on $(\mathrm{La} / \mathrm{Yb})_{\mathrm{n}}-(\mathrm{Eu} / \mathrm{Eu} *)_{\mathrm{n}}$ and $\mathrm{Sr}-$ $(\mathrm{Eu} / \mathrm{Eu} *)_{\mathrm{n}}$ diagrams, in the area of Akdağmadeni fluorites on $\mathrm{Sc} / \mathrm{Eu}-\mathrm{Sr}$ diagram and in the area of heavy metals on $\mathrm{Sc}-\sum \mathrm{REE}$ diagram respectively.
\end{abstract}

Key words: Fluorite, Aladağ unit, Sarıveliler (Karaman), rare earth element (REE).

\section{Giriş}

Türkiye'deki ana tektonik kuşaklardan birisi Toros Orojenik Kuşağı'dır [1]. Bu Kuşağın kuzeyini Anatolidler, güneyini ise Akdeniz ve Arap Platformu'na ait kenar kıvrımları sınırlamaktadır. Türkiye'nin paleotektonik sınıflamasında Okay ve Tüysüz [2], Toros Orojenik Kuşağı'nı Anatolid-Torid Bloğu içerisinde göstermektedir. Toros Orojenik Kuşağı coğrafik olarak ise batı, orta ve doğu olmak üzere 3 bölümden oluşmaktadır (Şekil 1a).

Orta Toroslar'da karbonatlı kayaçlar ile ilişkili Zn-Pb yatakları birçok araştırmacı tarafindan incelenmiştir [3 - 9]. Bu yataklarda genel olarak parajenezde baritle beraber florit de bulunmaktadır. Kuşçu [4] inceleme alanına yakın bir alanda bulunan Göktepe (Karaman) civarındaki $\mathrm{Zn}-\mathrm{Pb}$ oluşumlarında parajenezde floritlerin gözlendiğini belirtmiştir. Kuşçu [3] Göktepe'nin kuzey alanlarında gözlenen floritlerin Y içeriklerinin düşük olması sebebiyle

\footnotetext{
* Sorumlu yazar: uras74@ gmail.com. Yazarların ORCID Numaras1: ${ }^{1}$ 0000-0001-5561-3275, ${ }^{2}$ 0000-0002-0510-2992, ${ }^{3} 0000-0002-8971$ 010X
} 
florit oluşumunda formasyon sularının etkili olduğunu belirtmiştir. Sarıveliler ilçesi (Karaman) batısında yüzlek veren Aladağ Birliğine ait karbonatlı kayaçlar içerisindeki florit zenginleşmelerinin (Şekil 1b) parajenezinde floritle beraber galenit, kuvars ve kalsit bulunmaktadır. İnceleme alanının Göktepe bölgesinin yaklaşık 9 km kuzeyinde bulunması ve benzer kayaçların bu bölgede de var olması sebebiyle Sarıveliler florit oluşumunun jeokimyasal kökeninin ortaya konulması önem arz etmektedir. Bu çalışma ile Sarıveliler floritlerinin kökensel oluşumu ilk kez, Nadir Toprak Element (NTE) değerlerine göre ortaya konulmuştur.

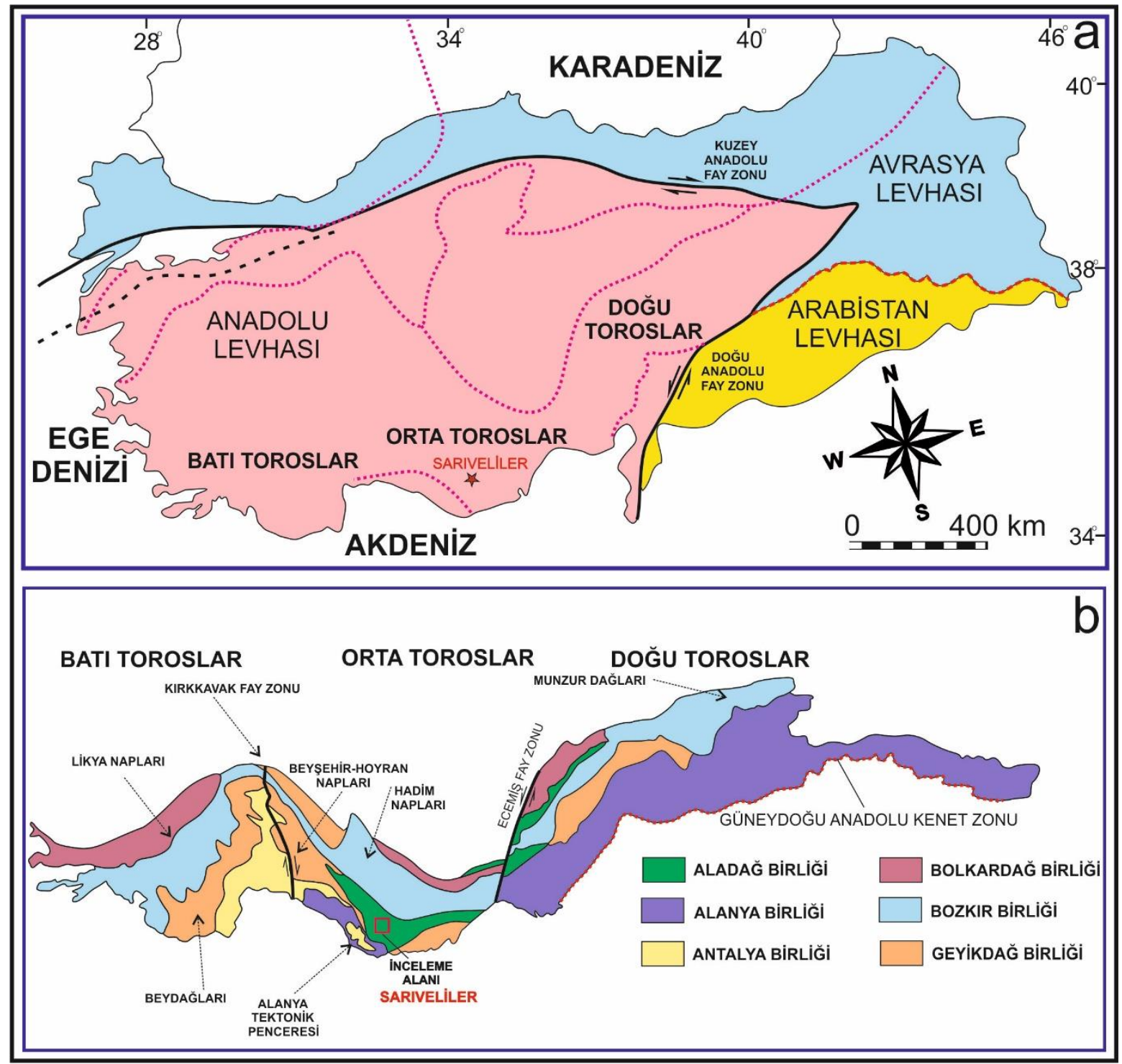

Şekil 1. İnceleme alanının Türkiye (a) ve Toroslardaki (b)tektonik konumu (Işık [10]'dan değiştirilmiştir).

\section{Ana Jeolojik Özellikler}

Toros Orojenik Kuşağı'nda Prekambriyen yaşlı temel kayaçlar ile Paleozoyik-Mesozoyik yaş aralığındaki kayaçlar, Geç Kretase'de Neotetis'in farklı kollarının da kapanmasıyla [11] bir araya gelmiş ve farklı tektonik dilimler oluşturmuştur [12 - 14]. Özgül [12] nap sistemlerinin yoğun olarak görüldüğü bu kuşaktaki tektonostratigrafik dilimleri stratigrafi, metamorfizma ve içyapı özelliklerini dikkate alarak Aladağ, Antalya, Alanya, Bozkır, Geyikdağı ve Bolkardağı birliklerine ayırmıştır.

Orta Toroslar'da bulunan inceleme alanı Sarıveliler ilçesinin (Karaman) batısında yer alır. İnceleme alanının temelini Aladağ Birliğine [12] ait litolojiler oluşturmaktadır (Şekil 2). Tabandan tavana doğru Haydar, Balcılar ve 
Çakozdağı formasyonundan oluşan Aladağ Birliği Tersiyer yaşlı sedimanter kayaçlar ile Kuvaterner yaşlı alüvyonlar tarafından açısal uyumsuzlukla örtülmektedir. İnceleme alanında geniş alanlarda görülen Haydar formasyonu [4] başlıca kumtaşı, çamurtaşı, killi kireçtaşı ve kireçtaşından oluşmaktadır. Aladağ Birliğine ait AltOrta Triyas yaşlı bu birim Demirtaşlı [15] tarafindan Göktepe formasyonu olarak da adlandırılmıştır. Ortaçal batısında birime ait kireçtaşları içerisindeki süreksizlik düzlemlerinde kurşunlu florit cevherleşmesi bulunmaktadır. Haydar formasyonuna ait litolojiler daha genç birimler tarafından açısal uyumsuzlukla örtülmektedir. Taban dokanağı Haydar formasyonu ile uyumsuz olan Üst Triyas Balcılar Formasyonu [4] başlıca kırmızımsı kahverengi konglomera, killi kireçtaşı, kumtaşı ve şeyllerden oluşmaktadır. Aladağ Birliği'ne ait JuraKretase yaşlı kireçtaşı, dolomitik kireçtaşı ve dolomitten oluşan Çakozdağı Formasyonu [17] Sarıveliler batısı ve Yayla evleri boyunca sınırlı alanlarda yüzlek vermektedir. Erken Oligosen yaşlı [18] Yenimahalle Formasyonu şeyl, marn, miltaşı, kumtaşı, çakıltaşı ardalanmasından oluşur ve Sarıveliler batısında yüksek tepelerde yüzeyleme vermektedir. İlk defa Gedik ve diğ. [19] tarafından adlandırılan Orta Miyosen yaşlı [20] Mut Formasyonu başlıca çakıltaşı, kumtaşı ve kireçtaşından oluşmakta ve yüksek rakımlı tepelerde yataya yakın tabakalar halinde gözlenmektedir.

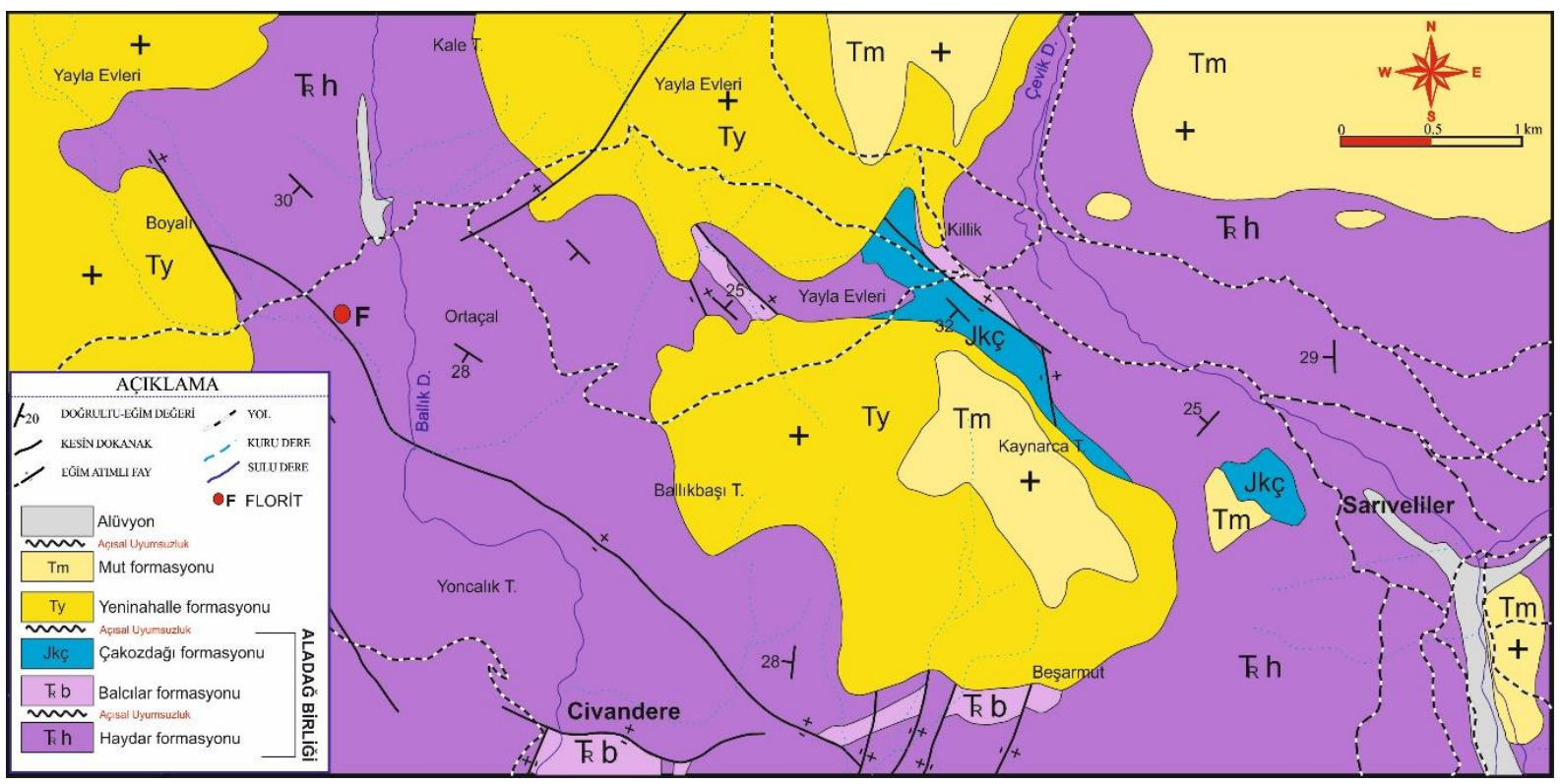

Şekil 2. İnceleme alanının jeoloji haritası (MTA'dan [16] değiştirilmiştir).

\section{Cevherleşme}

Sarıveliler florit cevherleşmesi Aladağ Birliği’ne ait Alt-Orta Triyas Haydar formasyonunda gözlenmektedir. Kireçtaşı seviyelerinde damar tipi (Şekil 3a) şeklinde gözlenen cevherleşme epijenetik oluşumludur. Damar kalınlıkları $3 \mathrm{~cm}$ ile $20 \mathrm{~cm}$ arasında değişmektedir. Kırık ve çatlaklarda gözlenen florite yer yer galenit (Şekil 3b) eşlik etmektedir. Bu bölgede gözlenen floritler mor ve saydam renklidir (Şekil 3c).

\section{Materyal ve Metot}

Sarıveliler civarında gözlenen birimlerin dokanak ilişkisini ortaya koymak amacıyla 1/25.000 ölçekli jeoloji haritası MTA [16]'dan değiştirilerek hazırlanmıştır. Sahadan alınan 12 adet florit örnekleri ise un haline getirilip 5'er gramlık numuneler halinde paketlenmiş ve Acme Laboratuvarına (Vancouer-Canada) gönderilmiştir. Floritlerin majör oksit, iz element, flor ve Nadir Toprak Elementi (NTE) analizi LIBBO2 FUSION cihazında, ICP/MS yöntemiyle gerçekleştirilmiş ve sonuçlar diyagramlarda değerlendirilmiştir. 


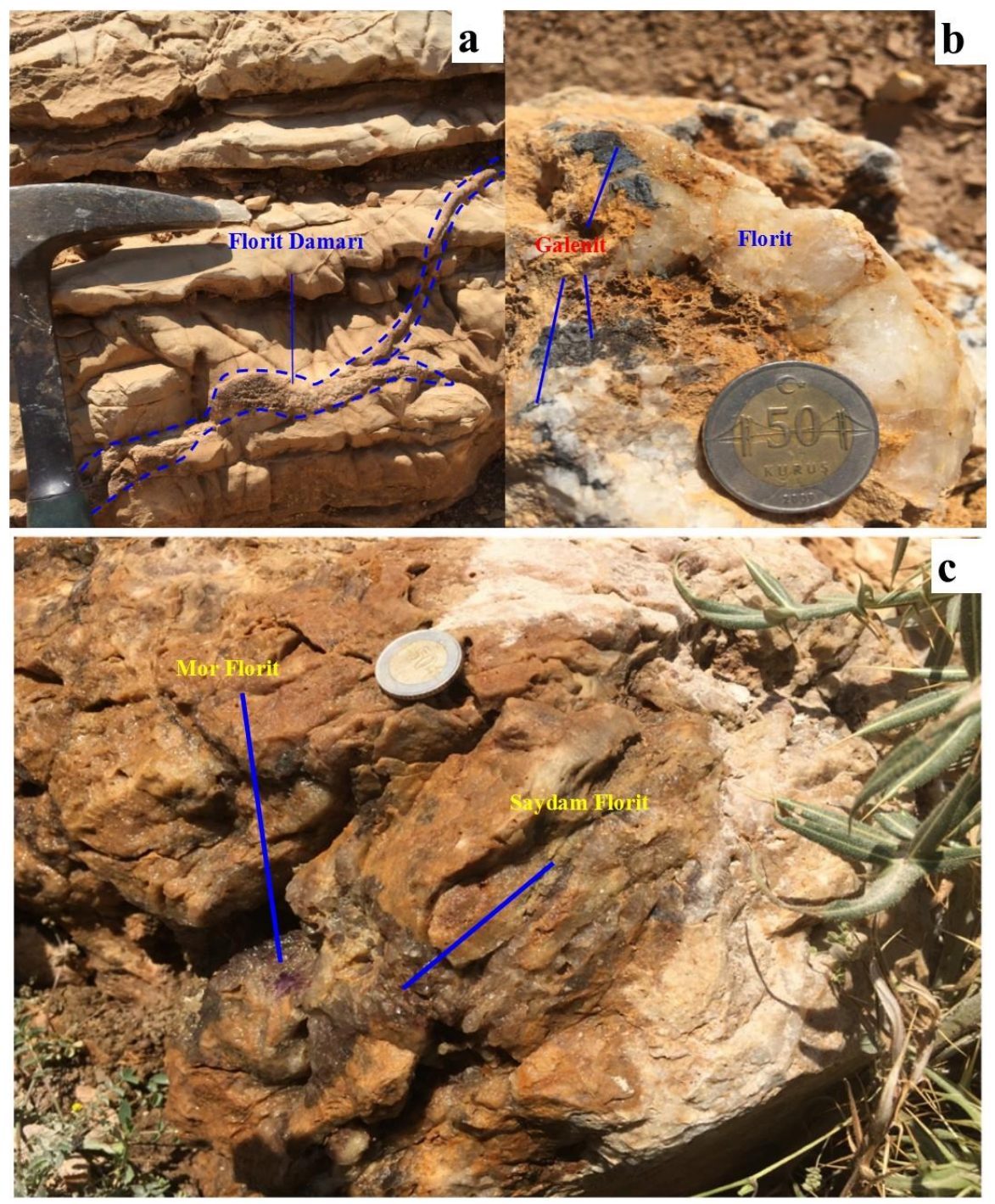

Şekil 3. Florit damarının (a), galenitin (b), saydam ve mor floritin (c) genel görünümü.

\section{Floritlerin NTE Jeokimyası}

Nadir toprak elementleri kayaçların ve maden yataklarının jenezinin ortaya konulması bakımından önemli bir parametredir. Kayaç içerisinde dolaşan çözelti karbonatça zengin bir akışkan ise bu durumda NTE normal sulu çözeltiden daha mobil bir karakter sergilemektedir [21]. Bu sebeple Sarıveliler floritlerinin nadir toprak elementi (NTE) analizi ile birlikte majör oksit, iz element ve florit analizi gerçekleștirilmiştir (Tablo 1). Analiz değerlerine göre Sarıveliler floritlerinde ortalama $28,65 \% \mathrm{~F}$ ve $50,34 \%$ Ca bulunmaktadır. Floritlerin NTE içerikleri 0,01 ile $11,5 \mathrm{ppm}$ arasında değişmekte ve toplamda ise $161,69 \mathrm{ppm} \Sigma \mathrm{NTE}$ bulunmaktadır. Bu durum floritlerin NTE bakımından fakir olduklarını ve Doğu Toroslar'daki Feke floritlerine benzer olduklarını göstermektedir [22]. Y değerleri ise Göktepe $\mathrm{Zn}-\mathrm{Pb}$ cevherleşmelerindeki floritlerin değerlerine [3] benzerlik göstermektedir. Kuşçu [3] $\mathrm{Y}$ değerinin çok küçük olmasına dayanarak floritlerin oluşumunun formasyon sularından kaynaklandığını belirtmiştir.

Floritlerin NTE içerikleri C1-Chondritlere [23] göre normalize edilmiş ve diyagramı hazırlanmıştır (Şekil 4). Diyagrama göre belirgin bir fraksiyonlaşmanın olmadığı, ağır nadir toprak elementlerinin (ANTE) geç evrede oluşan minarellerde bir zenginleşme gösterdiği, orta nadir toprak elementleri (ONTE) içeriklerinin yüksek değerler sunduğu ve hafif nadir toprak elementlerinin (HNTE), ONTE ve ANTE değerlerine göre daha az zenginleştiği belirlenmiştir. 
Tablo 1. Floritlerin majör oksit, flor ve iz element analiz sonuçları.

\begin{tabular}{|c|c|c|c|c|c|c|c|c|c|c|c|c|}
\hline $\mathbf{A}$ & SF-1 & SF-2 & SF-3 & SF-4 & SF-5 & SF-6 & SF-7 & SF-8 & SF-9 & SF-10 & SF-11 & SF-12 \\
\hline $\mathrm{SiO}_{2}(\%)$ & 0,18 & 0,14 & 0,13 & 0,14 & 0,15 & 0,15 & 0,10 & 0,08 & 0,24 & 0,12 & 0,22 & 0,14 \\
\hline $\mathrm{Al}_{2} \mathrm{O}_{3}(\%)$ & $<0,01$ & $<0,01$ & $<0,01$ & $<0,01$ & $<0,01$ & $<0,01$ & $<0,01$ & $<0,01$ & $<0,01$ & $<0,01$ & 0,03 & $<0,01$ \\
\hline $\mathrm{Fe}_{2} \mathrm{O}_{3}(\%)$ & 0,16 & 0,10 & 0,10 & 0,08 & 0,04 & 0,09 & 0,06 & 0,10 & 0,05 & 0,06 & $<0,04$ & 0,08 \\
\hline $\mathrm{Na}_{2} \mathrm{O}(\%)$ & 0,02 & 0,02 & 0,02 & 0,02 & 0,02 & 0,02 & 0,02 & 0,02 & 0,02 & 0,02 & 0,02 & 0,02 \\
\hline $\mathrm{K}_{2} \mathrm{O}(\%)$ & $<0,01$ & $<0,01$ & $<0,01$ & $<0,01$ & $<0,01$ & $<0,01$ & $<0,01$ & $<0,01$ & $<0,01$ & $<0,01$ & 0,01 & $<0,01$ \\
\hline $\mathrm{P}_{2} \mathrm{O}_{5}(\%)$ & $<0,01$ & $<0,01$ & $<0,01$ & $<0,01$ & $<0,01$ & $<0,01$ & $<0,01$ & $<0,01$ & $<0,01$ & $<0,01$ & $<0,01$ & $<0,01$ \\
\hline $\operatorname{MgO}(\%)$ & $<0,01$ & 0,01 & 0,01 & 0,01 & $<0,01$ & $<0,01$ & 0,01 & 0,01 & $<0,01$ & 0,06 & $<0,01$ & 0,07 \\
\hline $\mathrm{CaO}(\%)$ & 70,15 & 70,82 & 69,88 & 70,83 & 71,36 & 70,24 & 70,00 & 70,73 & 69,13 & 70,97 & 71,25 & 70,61 \\
\hline $\operatorname{MnO}(\%)$ & $<0,01$ & $<0,01$ & $<0,01$ & $<0,01$ & $<0,01$ & $<0,01$ & $<0,01$ & $<0,01$ & $<0,01$ & $<0,01$ & $<0,01$ & $<0,01$ \\
\hline $\mathrm{TiO}_{2}(\%)$ & $<0,01$ & $<0,01$ & $<0,01$ & $<0,01$ & $<0,01$ & $<0,01$ & $<0,01$ & $<0,01$ & $<0,01$ & $<0,01$ & $<0,01$ & $<0,01$ \\
\hline $\mathrm{F} \%$ & 28.95 & 28,31 & 29,22 & 28,18 & 27,91 & 28,8 & 29,3 & 28,52 & 30,14 & 28,15 & 28 & 28,38 \\
\hline Sr (ppm) & 69,3 & 66,9 & 69,5 & 68,5 & 68,6 & 65,1 & 68,8 & 62,2 & 59,8 & 69,4 & 70,0 & 66,4 \\
\hline $\mathrm{Ca}$ & 50,10 & 50,58 & 49,91 & 50,59 & 50,97 & 50,17 & 50 & 50,5 & 49,35 & 50,69 & 50,89 & 50,43 \\
\hline Ni(ppm) & 0,5 & $<0,1$ & $<0,1$ & $<0,1$ & 0,4 & $<0,1$ & $<0,1$ & $<0,1$ & $<0,1$ & $<0,1$ & $<0,1$ & $<0,1$ \\
\hline $\mathrm{Zr}$ (ppm) & 0,8 & 0,6 & 0,7 & 0,6 & 0,5 & 0,4 & 0,5 & 0,8 & 1,8 & 0,5 & 0,7 & 0,7 \\
\hline Th (ppm) & 0,6 & 0,6 & 0,8 & 0,8 & 0,6 & 0,5 & 0,6 & 0,5 & 0,7 & 0,6 & 1,0 & 0,4 \\
\hline $\mathrm{As}(\mathrm{ppm})$ & 1,7 & 0,7 & 0,6 & $<0,5$ & $<0,5$ & 0,5 & 1,2 & 0,7 & $<0,5$ & $<0,5$ & $<0,5$ & 0,8 \\
\hline Cd(ppm) & 10,5 & 9,2 & 12,1 & 13,2 & 11,0 & 15,5 & 10,5 & 16,6 & 12,3 & 9,3 & 1,5 & 9,8 \\
\hline W (ppm) & 1,4 & 1,2 & 0,9 & $<0,5$ & 0,8 & $<0,5$ & 0,5 & 1,3 & $<0,5$ & 0,5 & 0,7 & 1,7 \\
\hline La (ppm) & 0,9 & 0,5 & 1,0 & 0,7 & 0,8 & 0,5 & 0,5 & 1,2 & 1,5 & 0,8 & 0,7 & 0,9 \\
\hline Ce (ppm) & 0,8 & 0,9 & 0,8 & 1,0 & 1,1 & 0,9 & 0,9 & 0,7 & 1,1 & 0,9 & 1,0 & 0,9 \\
\hline $\operatorname{Pr}(\mathrm{ppm})$ & 0,18 & 0,21 & 0,19 & 0,21 & 0,18 & 0,18 & 0,20 & 0,16 & 0,17 & 0,16 & 0,18 & 0,16 \\
\hline Au(ppm) & $<0,5$ & $<0,5$ & $<0,5$ & 1,2 & $<0,5$ & 4,7 & 1,1 & $<0,5$ & $<0,5$ & $<0,5$ & 1,0 & 1,0 \\
\hline Nd (ppm) & 0,8 & 0,9 & 1,0 & 1,1 & 0,9 & 1,2 & 1,2 & 1,3 & 0,7 & 1,0 & 1,0 & 1,2 \\
\hline Sm (ppm) & 0,35 & 0,35 & 0,40 & 0,37 & 0,33 & 0,34 & 0,39 & 0,34 & 0,49 & 0,40 & 0,55 & 0,37 \\
\hline Eu (ppm) & 0,14 & 0,14 & 0,11 & 0,12 & 0,14 & 0,11 & 0,10 & 0,15 & 0,11 & 0,12 & 0,15 & 0,13 \\
\hline Tb (ppm) & 0,12 & 0,10 & 0,11 & 0,11 & 0,11 & 0,11 & 0,10 & 0,11 & 0,11 & 0,10 & 0,14 & 0,10 \\
\hline Dy (ppm) & 0,52 & 0,61 & 0,56 & 0,77 & 0,75 & 0,65 & 0,69 & 0,67 & 0,62 & 0,65 & 0,94 & 0,46 \\
\hline Ho (ppm) & 0,12 & 0,13 & 0,14 & 0,12 & 0,09 & 0,10 & 0,11 & 0,12 & 0,014 & 0,14 & 0,15 & 0,12 \\
\hline $\operatorname{Er}(\mathbf{p p m})$ & 0,35 & 0,24 & 0,28 & 0,32 & 0,26 & 0,29 & 0,23 & 0,25 & 0,30 & 0,26 & 0,38 & 0,26 \\
\hline $\mathbf{B a}(\mathbf{p p m})$ & 22 & 10 & 13 & 15 & 11 & 11 & 13 & 12 & 18 & 18 & 19 & 11 \\
\hline Tm (ppm) & 0,14 & 0.03 & 0.03 & 0.03 & 0.03 & 0,03 & 0.03 & 0.03 & 0,03 & 0,04 & 0,05 & 0,04 \\
\hline Co(ppm) & 0,9 & 0,4 & 0,9 & 0,8 & 0,5 & 0,6 & 1,0 & 0,8 & 1,1 & 0,4 & 1,5 & 0,7 \\
\hline Yb (ppm) & 0,17 & 0,16 & 0,16 & 0,24 & 0,16 & 0,11 & 0,12 & 0,19 & 0,11 & 0,13 & 0,24 & 0,17 \\
\hline $\mathbf{Y}(\mathbf{p p m})$ & 9,8 & 9,3 & 9,2 & 10,5 & 10,2 & 9,5 & 10,6 & 9,5 & 9,4 & 9,2 & 11,5 & 9,6 \\
\hline $\mathrm{Cs}(\mathrm{ppm})$ & 0,1 & 0,1 & 0,2 & $<0,1$ & 0,2 & 0,2 & $<0,1$ & 0,2 & 0,2 & 0,2 & 0,1 & $<0,1$ \\
\hline $\mathrm{Nb}$ (ppm) & $<0,1$ & 0,3 & 0,4 & 0,6 & 0,7 & 0,8 & 0,6 & 1,1 & 0,8 & 0,5 & 0,4 & 0,4 \\
\hline $\mathbf{R b}(\mathbf{p p m})$ & 1,3 & 1,5 & 1,6 & 1,5 & 1,5 & 1,4 & 1,3 & 1,4 & 1,4 & 1,3 & 1,6 & 1,3 \\
\hline Se(ppm) & 0,7 & 1,7 & 1,0 & 2,1 & 0,6 & 0,9 & 1,4 & 0,9 & 1,4 & 0,6 & 0,5 & 1,9 \\
\hline $\mathrm{Nb}(\mathbf{p p m})$ & 1,6 & 0,7 & 1,3 & 0,7 & 1,3 & $<0,1$ & 0,8 & 0,5 & 0,1 & $<0,1$ & 1,0 & 0,7 \\
\hline $\mathrm{Hg}(\mathrm{ppm})$ & 0,05 & 0,04 & 0,07 & 0,11 & 0,04 & 0,08 & 0,08 & 0,04 & 0,05 & 0,07 & 0,08 & 0,07 \\
\hline$V(p p m)$ & 23 & 25 & 9 & 8 & 8 & 18 & 18 & 11 & $<8$ & $<8$ & 8 & 9 \\
\hline Gd(ppm) & 0,82 & 0,79 & 0,78 & 0,71 & 0,82 & 0,76 & 0,64 & 0,75 & 0,81 & 0,66 & 0,98 & 0,77 \\
\hline Lu (ppm) & 0,02 & 0.03 & 0.02 & 0.03 & 0,02 & 0,02 & 0,02 & 0,02 & 0,01 & 0,03 & 0,03 & 0,02 \\
\hline Mo(ppm) & 0,4 & 0,4 & 0,2 & 0,2 & 0,1 & 0,2 & 0,3 & 0,2 & 0,1 & 0,3 & 0,2 & 0,3 \\
\hline $\mathrm{Cu}(\mathrm{ppm})$ & 1,4 & 0,9 & 1,1 & 1,3 & 1,1 & 1,2 & 0,6 & 0,7 & 0,8 & 1,0 & 0,6 & 0,9 \\
\hline $\mathrm{Zn}(\mathbf{p p m})$ & 1669 & 1234 & 1564 & 1810 & 1594 & 2023 & 1422 & 1952 & 1520 & 1342 & 384 & 1260 \\
\hline $\mathrm{Pb}(\mathrm{ppm})$ & 32,6 & 39,8 & 79,0 & 62,5 & 45,4 & 59,0 & 32,0 & 52,0 & 41,5 & 49,6 & 27,9 & 67,6 \\
\hline CelYb & 4,70 & 5,62 & 5 & 4,16 & 6,87 & 0,18 & 7,5 & 3,68 & 10 & 6,92 & 4,16 & 5,29 \\
\hline Tb\La & 0,13 & 0,2 & 0,1 & 0,15 & 0,13 & 0,22 & 0,2 & 0,09 & 0,07 & 0,125 & 0,2 & 0,11 \\
\hline Tb\} \backslash C a ^ { * } 1 0 - { } ^ { 7 } $&{2,39} &{1,97} &{2,20} &{2,17} &{2,15} &{2,19} &{2} &{2,17} &{2,22} &{1,97} &{2,75} &{1,98} \\
{\hline \text { CelCe* }} &{0,605} &{0,506} &{0,449} &{0,639} &{0,710} &{0,735} &{0,697} &{0,391} &{0,534} &{0,616} &{0,690} &{0,581} \\
{\hline \mathbf{E u} / \mathbf{E u} \mathbf{u}^{*}} &{0,799} &{0,814} &{0,602} &{0,716} &{0,823} &{0,662} &{0,612} &{0,909} &{0,534} &{0,714} &{0,625} &{0,745} \\
{\hline \Sigma \text { ENTE }} &{14,33} &{13,89} &{13,78} &{15,63} &{15,09} &{14,30} &{15,33} &{14,29} &{13,97} &{13,79} &{17,29} &{14,30} \\
$\hline
\end{tabular}




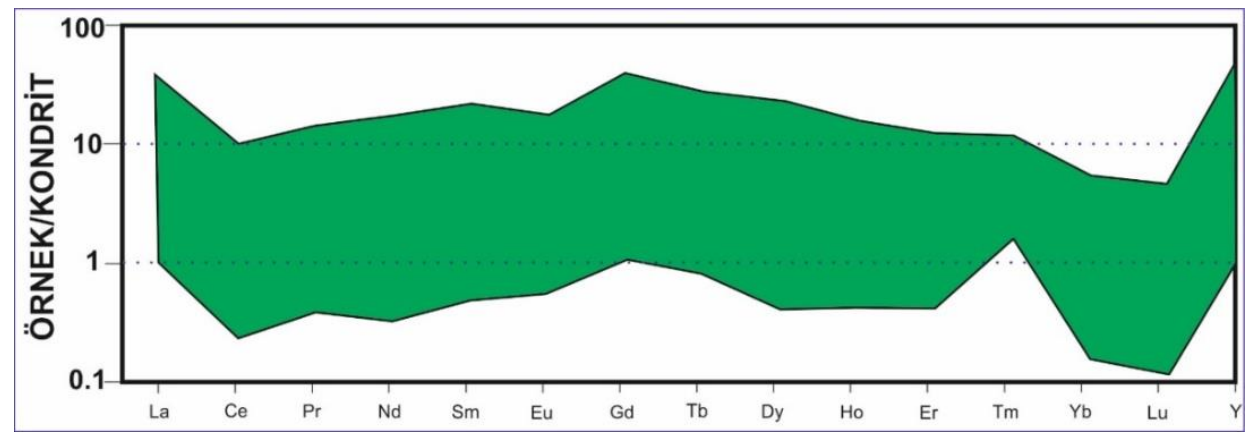

Şekil 4. Sarıveliler floritlerinin kondritlere göre normalleştirilmiş Lantanid diyagramı.

$\mathrm{Eu} / \mathrm{Eu}^{*}$ ve $\mathrm{Ce} / \mathrm{Ce}$ * oranları cevherleşme ortamının oksijen içeriği hakkında önemli bilgiler sunmaktadır [21]. $\mathrm{Ce} / \mathrm{Ce}^{*}$ ve $\mathrm{Eu} / \mathrm{Eu}^{*}$ oranları $\mathrm{Ce} / \mathrm{Ce}^{*}=\mathrm{Ce}_{\mathrm{n}} /(\mathrm{Lan} \mathrm{x} \text { Prn })_{1 / 2}$ ve $\mathrm{Eu} / \mathrm{Eu}^{*}=\mathrm{Eu}_{\mathrm{n}} /\left(\mathrm{Sm}_{\mathrm{n}} \mathrm{x} \mathrm{Gd}_{\mathrm{n}}\right)_{1 / 2}$ şeklinde hesaplanmaktadır [24 - 27]. Eu/Eu* değerleri $>1$ ise ortamda yeteri miktarda oksijen olması durumunda $\mathrm{Eu}^{+2}$ oksitlenerek $\mathrm{Eu}^{+3}$ 'e dönüşür ve floritlerin yapısına girer [25]. $\mathrm{Ce} / \mathrm{Ce}^{*}$ değerleri $<1$ ise $\mathrm{Ce}$ oksijenle birleşerek $\mathrm{CeO}^{2}$ şeklinde çökelir ve böylece floritlerin yapısına giremez. Bu sebeple Kondrite göre normalize edilmiş diyagramlarda $\mathrm{Ce}$ negatif, Eu ise pozitif bir anomali sunmaktadır [23]. Floritlerde pozitif Ce anomalisi gözlenmesi hidrotermal sıvıların kaynağında düşük oksijen fugasitesinin varlığını, negatif Eu anomalisi gözlenmesi ise bu koşulların cevherleşme ortamında da devam ettiğini göstermektedir [28, 29]. Sarıveliler floritlerinde Eu açısından küçük miktarda bir zenginleşme görülmektedir. Negatif Ce anomalisi ise yüksek oksijen fugasitesine işaret etmektedir.

Sarıveliler floritleri formasyon sularının etkisi altında oluşmuştur. Kuşçu [3] Göktepe civarındaki floritlerin Y içeriğinin fakir olduğunu, bu sebeple florit oluşturan akışkanın magmatik kökenli olmadığını ve cevherleşmede formasyon sularının etkili olduğunu belirtmiştir. Bu bakımdan Sarıveliler floritleri Göktepe floritlerine benzer bir karakter sunmaktadir.

Florit oluşumu anında Lantanyum ( $\mathrm{La}$ ) ve Terbiyum $(\mathrm{Tb})$ yoğun bir ayrımlanmaya uğramaktadır. Bu nedenle $\mathrm{Tb} / \mathrm{La}$ ve $\mathrm{Tb} / \mathrm{Ca}$ oranları, oluşum ortamlarının ve ayrımlanma derecesinin belirlenmesinde ve oluşum ortamının belirlenmesinde kullanılmaktadır [30, 24, 28]. Floritlerin kökensel olarak belirlenmesi için kullanılan $\mathrm{Tb} / \mathrm{Ca}$ Tb/La diyagramında [30] Sarıveliler floritlerinin hidrotermal kökenli olduğu görülmektedir (Şekil 5).

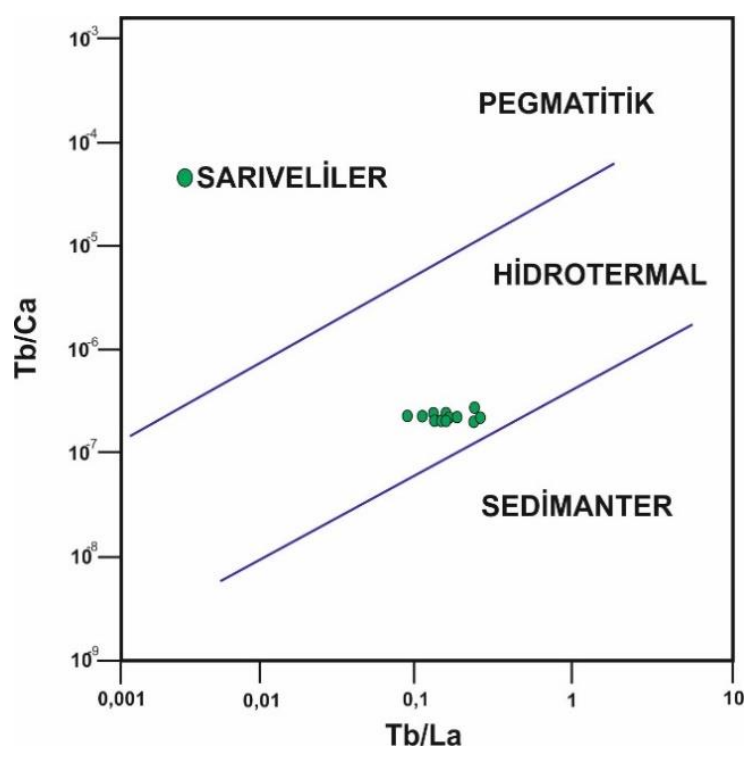

Şekil 5. Sarıveliler floritlerinin $\mathrm{Tb} / \mathrm{La}-\mathrm{Tb} / \mathrm{Ca}$ [28] diyagramındaki yeri.

Sarıveliler floritlerinin NTE jeokimyası değerlerine göre, floritler $(\mathrm{Tb} / \mathrm{Yb})_{\mathrm{n}}-(\mathrm{La} / \mathrm{Yb})_{\mathrm{n}}$ diyagramında [31] Hill vd., [32] tarafından öne sürülen kristalize edilmiş bölgede dağılım göstermekte (Şekil 6), $(\mathrm{La} / \mathrm{Yb})_{\mathrm{n}}$ ve $(\mathrm{Eu} / \mathrm{Eu})_{\mathrm{n}}$ 
oranlarının karşılaştırılmasıyla elde edilen diyagramda ise Büyükkızılcık floritleri [33] ile yaklaşık aynı bölgede dağılım göstermektedir (Şekil 7).

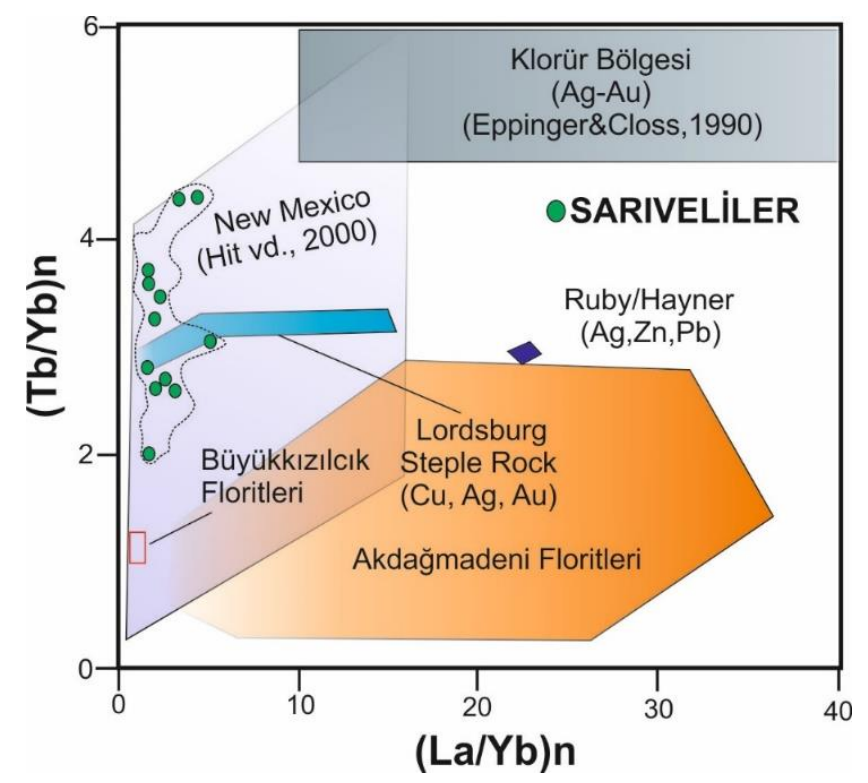

Şekil 6. $(\mathrm{Tb} / \mathrm{Yb})_{\mathrm{n}}$ ve $(\mathrm{La} / \mathrm{Yb})_{\mathrm{n}}$ oranlarının karşılaştııılması sonucu Sarıveliler floritlerinin dağılımı (Şaşmaz vd., [31]'den değiştirilmiştir).

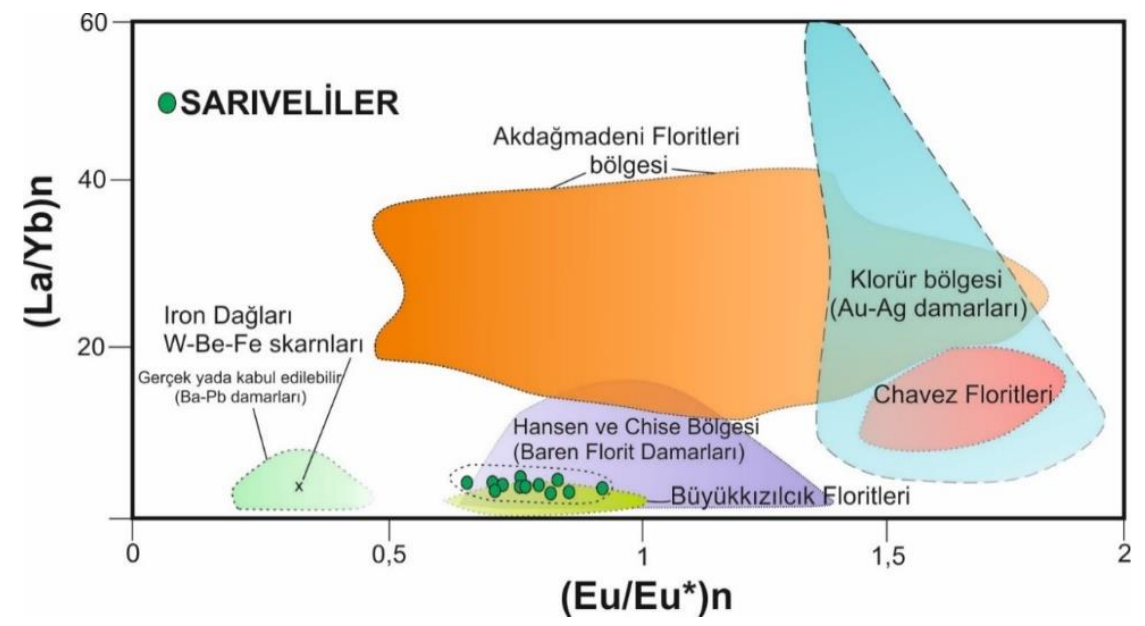

Şekil 7. $(\mathrm{La} / \mathrm{Yb})_{\mathrm{n}}$ ve $\left(\mathrm{Eu} / \mathrm{Eu}{ }^{*}\right)_{\mathrm{n}}$ diyagramında Sarıveliler floritlerinin dağılımı (Şaşmaz vd., [31] ve Uras ve Çalışkan, [33]'ten değiştirilmiştir).

$\mathrm{Sc} / \mathrm{Eu}$ ve Sr diyagramında [31] Sarıveliler floritleri, Akdağmadeni floritleri alanında dağılım göstermektedir (Şekil 8). Sr-(Eu/Eu*)n değerlerinin karşılaştırılmasıyla elde edilen diyagramda ise $\mathrm{Eu} / \mathrm{Eu}{ }^{*}$ değerlerinin negatif yönde olması florit oluşumunda ortamda oksijenin az olduğunu ve bu özelliği ile Büyükkızılcık floritleri ile benzer dağılım gösterdiği belirlenmiş̧tir (Şekil 9). Sc ve Toplam NTE oranlarının karşılaştırılması ile Sarıveliler floritlerinin NTE bakımından oldukça fakir bir bölgeye düştüğü ve ağır metallere benzer dağılım gösterdiği belirlenmiştir (Şekil 10). 
Rare Earth Element Geochemistry Of Sarıveliler (Karaman) Fluorites Related To Carbonate Rocks in Middle Taurus

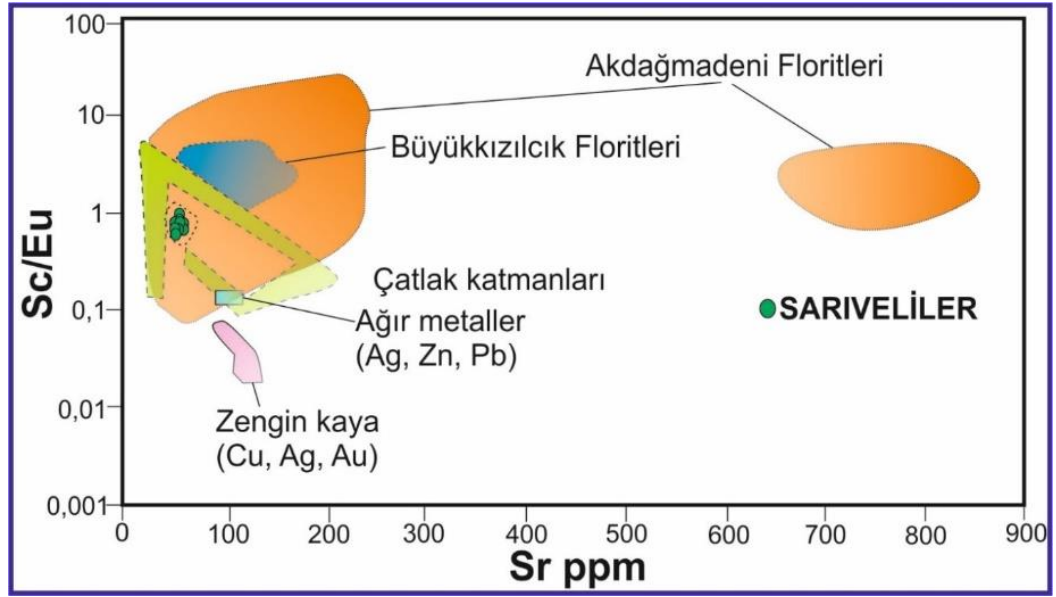

Şekil 8. Sr-Sc/Eu diyagramında floritlerin dağılımı (Şaşmaz vd., [31] ve Uras ve Çalışkan, [33]'ten değiştirilmiştir).

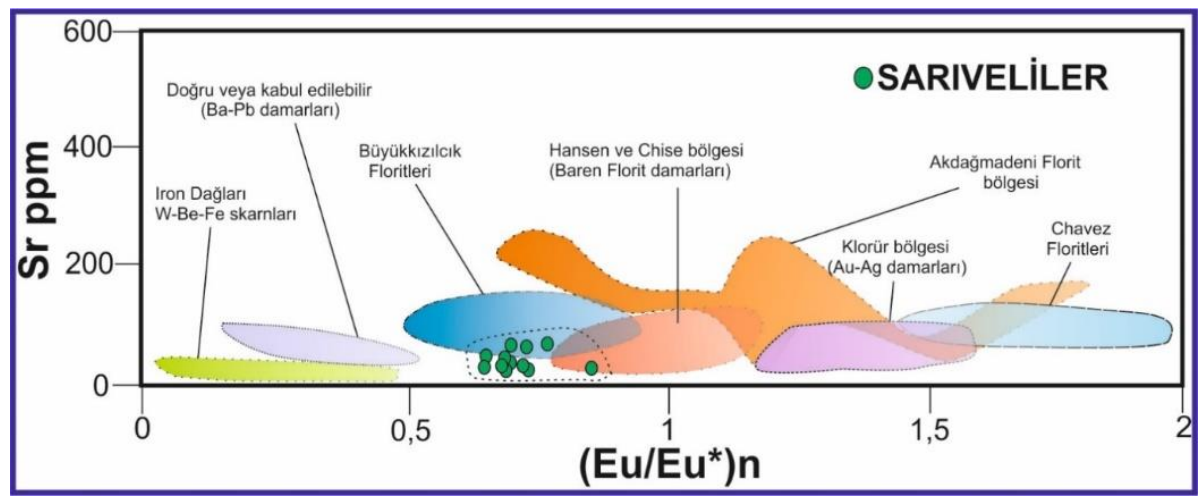

Şekil 9. $\mathrm{Sr}-\left(\mathrm{Eu} / \mathrm{Eu}^{*}\right)_{\mathrm{n}}$ diyagramında floritlerin dağılımı (Şaşmaz vd., [31] ve Uras ve Çalışkan, [33]'ten değiştirilmiştir).

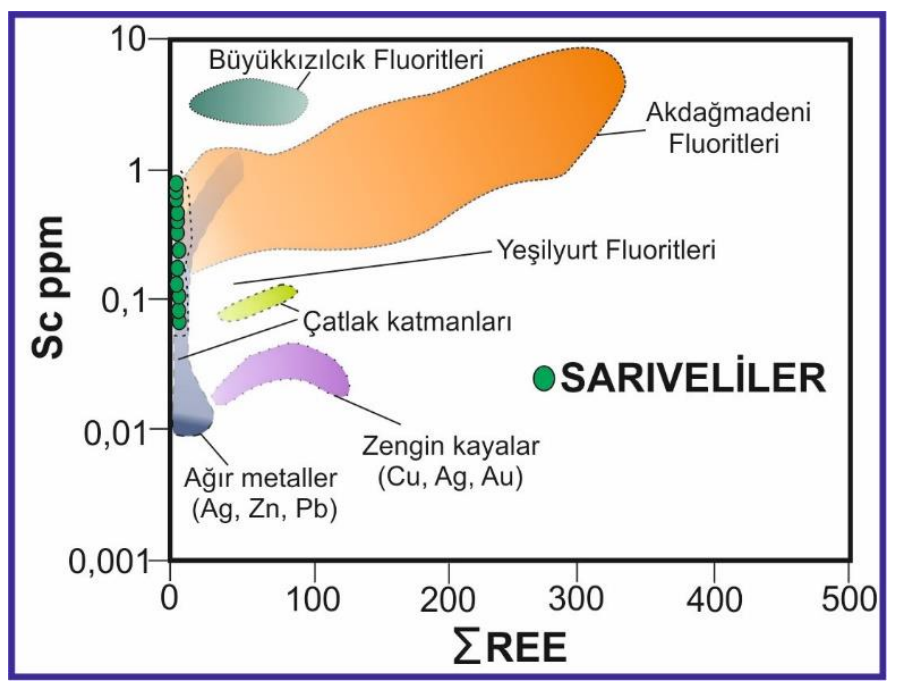

Şekil 10. Toplam nadir toprak elementi ( $(R E E)$ ve Sc (ppm) diyagramı (Şaşmaz vd., [31] ve Uras ve Çalışkan, [33]'ten değiştirilmişsir). 


\section{Sonuçlar}

Altuncu [34], Türkiye florit yataklarının oluşumlarını karşılaş̧ırmalı olarak incelemiş ve Toros Orojenik kuşağ 1 içerisinde gözlenen floritlerin oluşum ortamı ve kökenine dair sonuçlar elde etmiştir. Coşanay vd., [35] ise Orta Anodolu'da gözlenen floritlerin mikrotermometrik özelliklerini ve jeokimyasal özelliklerini ortaya koymuştur. Azizi vd., [36] İran'da Markazi bölgesindeki floritleri incelemiş ve damar tipi şeklindeki floritlerin NTE bakımından fakir olduğunu ve parajenezde dolomit, barit, hematit, götit ve az miktarda pirit gözlendiğini belirtmiştir.

Bu çalışma ile Orta Toroslar'da Aladă̆ Birliği içerisindeki Erken-Orta Triyas yaşlı Haydar Formasyonu'nda gözlenen Sarıveliler floritlerinin epijenetik oluşumlu ve damar tipi şeklinde olduğu belirlenmiştir. Mor ve saydam renkli floritler Haydar Formasyonu'na ait kireçtaşları içerisindeki kırık düzlemlerinde gözlenmektedir. Yapılan analizlerde F ortalama \%28,65 ve Ca \%50,34 civarındadır. Parajenezde florit, galenit, kuvars ve kalsit bulunmaktadır. Sarıveliler floritleri yakın güneyindeki Göktepe floritlerine $[3,4]$ benzer jeolojik ve jeokimyasal özellikler sunmaktadır. Ancak Göktepe floritleri parajenez açısından daha zengindir. Floritlerin NTE kimyasına göre oluşumu kırık hatlarında dolaşan hidrotermal suları işaret etmektedir. Düşük Y değeri Göktepe civarındaki floritlerin Y içeriğine benzer olup florit oluşturan akışkanın formasyon suları olduğu belirlenmiştir [3]. Sarıveliler floritlerinde Eu açısından küçük miktarda bir zenginleşme görülmektedir. Negatif Ce anomalisi ise yüksek oksijen fugasitesine işaret etmektedir.

Sarıveliler floritleri diyagramlarda dünyada bilinen diğer yataklar ile karşılaştırılmıştır. Floritlerin $(\mathrm{Tb} / \mathrm{Yb})_{\mathrm{n}}-$ $(\mathrm{La} / \mathrm{Yb})_{\mathrm{n}}$ diyagramında New Mexico kristalize alanında, $(\mathrm{La} / \mathrm{Yb})_{\mathrm{n}}-(\mathrm{Eu} / \mathrm{Eu} *)_{\mathrm{n}}$ ve $\mathrm{Sr}-\left(\mathrm{Eu} / \mathrm{Eu}{ }^{*}\right)_{\mathrm{n}}$ diyagramlarında Büyükkızılcık floritlerine benzer alanda, $\mathrm{Sc} / \mathrm{Eu}-\mathrm{Sr}$ diyagramında Akdağmadeni floritleri alanında ve $\mathrm{Sc}-\sum \mathrm{REE}$ diyagramında ise ağır metaller alanında dağılım gösterdiği belirlenmiştir.

\section{Teşekkür}

Bu çalışma Kahramanmaraş Sütçü İmam Üniversitesi, Bilimsel Araştırma Projeleri Koordinasyon Birimi tarafindan desteklenmiştir. Proje No:2014/2-10YLS.

\section{Kaynaklar}

[1] Ketin İ. Anadolu'nun tektonik birlikleri. MTA Dergisi 1966; 66: 20-34.

[2] Okay A, Tüysüz O. Tethyan sutures of northern Turkey. In: B. Durand, J L. Olivet, E. Horvath and M. Serrane (Eds.), The Mediterranean basins, extension within the Alpine Orogen. Geol. Soc. London Spec. Publ. 1999. 156: 475-515.

[3] Kuşçu M. Göktepe (Ermenek - Konya) kuzey kesimi Pb - Zn zuhurlarındaki floritlerin Y (Yitriyum) içerikleri. Bulletin of The Geological Society of Turkey 1984; 27: 57-60.

[4] Kuşçu M. Göktepe (Ermenek-Konya) yöresinin Pb-Zn zuhurları. TJK bülteni 1985; 28: 35-46.

[5] Kuşçu M, Cengiz O. Karbonatlı kayaçlara bağlı Orta Toroslar Zn-Pb cevherleşmelerinin kükürt izotopları incelemesi. TJK Bülteni 2001; 44(3): 59-73.

[6] Hanilçi N. Formation of the carbonate-hosted $\mathrm{Pb}-\mathrm{Zn}$ deposits in Central and Eastern Taurus [unpublished Ph.D. thesis]: Natural Science Institute, Istanbul University 2003; p. 166, Istanbul.

[7] Gökçe A, Bozkaya G. Karalar (Gazipaşa-Antalya) barit-galenit yataklarının jeolojisi ve sıvı kapanım özellikleri. Türkiye Jeoloji Bülteni 2003; 46: 1.

[8] Cengiz O, Kuşçu M. Geological properties of galena-bearing barite and barite deposits in the central Taurides. 41st Forum on the Geology of Industrial Minerals 2005.

[9] Gümüş L, Kumral M, Yalçın C, Kaya M, Ünlüer TA, Öztürk S, Karaman M. Aladağ birliği (Çayarası-Alanya) içerisinde karbonatlı kayaçlar ile ilişkili baritli $\mathrm{Zn}-\mathrm{Pb}$ cevherleşmesinin jeolojisi ve jeokimyası. Ömer Halisdemir Üniversitesi Mühendislik Bilimleri Dergisi, Kapadokya Yerbilimleri Sempozyumu Özel Sayıs1 2018; 7(3): 1209-1213, doi: 10.28948/ngumuh.502461.

[10] Işı1k V. Torosların Jeolojisi; Türkiye Jeolojisi Ders Notu. Ankara Üniversitesi, Jeoloji Mühendisliği Bölümü, 2016, Ankara.

[11] Şengör AMC, Y1lmaz Y. Tethyan evolution of Turkey, a plate techtonic approach. Techtonophysics 1981; 75: 81-241.

[12] Özgül N. Torosların bazı temel jeolojik özellikleri. T.J.K. Bül. 1976; 19: 65-78.

[13] Göncüooğlu MC, Dirik K, Kozlu H. Pre- Alpine and Alpine Terranes in Turkey: Explanatory notes to the terrane map of Turkey. Annales Ge'ologique Pays Helle'nique 1997; 37: 515-536.

[14] Bozkaya Ö, Yalçın H.. Diagenetic to low-grade metamorphic evolution of clay mineral assamblages in Paleozoic to early Mesozoic rocks of Eastern Taurides, Turkey. Clay Minerals 2004; 39: 481-500.

[15] Demirtaşlı E. Pınarbaşı, Sarız ve Tufanbeyli ilçeleri arasında kalan yörenin jeolojisi: İ:Ü.F.F.Min. Ve Petr. Kürs. (Bitirme Ödevi) 1979; 30 Sayfa. Yayınlanmamış, İstanbul. 
[16] MTA. Alanya O29 d1 paftası. 1:25.000 ölçekli Jeoloji Haritası.

[17] Demirtaşlı E. Toros kuşağının petrol potansiyeli. Türkiye 3. Petrol Kongresi Bildiriler Kitabı 1976; S. 55- 61, Ankara.

[18] Tanar Ü, Gökçen N. Mut-Ermenek Tersiyer istifinin stratigrafisi ve mikropaleontolojisi. Maden Tetkik ve Arama Dergisi $1990 ; 110 ; 175-180$.

[19] Gedik A, Birgili Ş, Yılmaz H, Yoldaş R. Mut-Ermenek-Silifke yöresinin jeolojisi ve petrol olanakları. TJK Bülteni 1979; 22: 7-26.

[20] Tanar Ü. Mut havzası Tersiyer istifinin stratigrafik ve mikropaleontolojik (Ostrokod ve foraminifer) incelemesi. Çukurova Üniv. Fen Bilimleri Enst. (Basılmamış Doktora Tezi) 1989; Adana.

[21] Rollinson H. Using geochemical data. library of Congress Catolog 1993.

[22] Uras Y. Feke (Adana) ve Bayındır (Kaman) fluoritlerinin nadir toprak elementlerinin karşılaştırılması. Çukurova Üniversitesi Fen Bilimleri Enstütisi Doktora tezi 2002; 86s.

[23] Evensen NM, Hamilton PJ, O'Nions RK. Rare-Earth abundances in chondritic meteorites. Geochimica et Cosmochimica Acta 1978; 42: 1199-1212.

[24] Möller P, Morteani G. On the geoehemical fractination of rare earth elements during the formation of Ca minerals and its application to problems of the genesis of ore deposits in Augustiths, In: S.S. (Ed)., The Significance of Trace Elements in Solving Petragenetic Problems and Controversies: Theophrastus Pub. 1983; 747-791, Athens.

[25] Constantopoulos J. Fluid inclusion and rare earth element geochemistry of florite from South-Central Idaho, Economic Geology 1988; 83: 626-636.

[26] Palmer DAS, Willams-Jones A.E. Genesis of the carbonatite hosted florite deposit at Amba Dongar, India, Evidence from fluid inclusions, stable isotopes and whole rock-mineral geochemistry. Econ. Geol 1996; 91: 934-950.

[27] Williams-Jones AE, Palmer DAS. Fluid evolution of the Amba Dongar carbonatite complex, India. Chem. Geol. 2002; 185: 283-301.

[28] Möller P, Parekh PP, Schneider HJ. The application of $\mathrm{Tb} / \mathrm{Ca}$, Tb/la abundance ratios to problems of fluorspar genesis. Min. Deposits 1976; 11: 111-116.

[29] Brookins D. Aqueous geochemistry of rare earth elements, in geochemistry and mineralogy of the rare earth elements, Reviews in Mineralogy 1989; 21: 201-225.

[30] Schneider HJ, Möller P, Parekh PP. Rare earth elements distribution in fluorites and carbonate sediments of the EastAlpine Mid Triassic sequences in the Nordliche Kalkalpen. Mineralium Deposita 1975;10: 330-344.

[31] Şaşmaz A, Yavuz F, Sağıroğlu A, Akgül B. Geochemical patterns of the Akdağmadeni (Yozgat, Central Turkey) fluorite deposits and implications. J. Asian Earth Sci 2005; 24: 469-479.

[32] Hill GT, Campell AR, Kyle PR. Geochemistry of southwestern New Mexico fluorite occurrences: Implications for precious metals exploration in fluorite bearing systems. J. Geochem. Expl 2000; 68: 1-20.

[33] Uras Y, Caliskan V. Geochemical patterns of the Buyukkizilcik (Kahramanmaras) fluorite deposits. Geochemistry International 2014; 52(12): 1087-1100.

[34] Altuncu S. Türkiye Fluorit Yataklarının Karşılaştırmalı İncelenmesi. İstanbul Üniversitesi Fen Bilimleri Enstitüsü Doktora Tezi 2009; 147 s. (yayımlanmamış).

[35] Coşanay P, Kirat E, Cevik N, Kizilkanat C, Mutlu H, Koç Ş. Geochemical, microthermometric, and isotopic constraints on the origin of fluorite deposits in central Anatolia, Turkey. Turkish Journal of Earth Sciences 2017; 26(3), 206-226.

[36] Azizi MR, Alipour S, Abedini A, Bagheri H. REE geochemical characteristics and fluid inclusion studies of the BagherAbad fluorite deposit, Central Iran. Neues Jahrbuch für Mineralogie-Abhandlungen: Journal of Mineralogy and Geochemistry 2018; 195(3), 247-263. 